\title{
LONG-TERM BOND STRENGTH OF ADHESIVE SYSTEMS APPLIED TO ETCHED AND DEPROTEINIZED DENTIN
}

\author{
Ninoshka UCEDA-GÓMEZ ${ }^{1}$, Alessandro Dourado LOGUERCIO², Sandra Kiss MOURA³, \\ Rosa Helena Miranda GRANDE ${ }^{4}$, Margareth ODA ${ }^{5}$, Alessandra REIS ${ }^{2}$
}

1- MSc, PhD student, Department of Operative Dentistry, School of Dentistry, University of São Paulo, São Paulo, SP, Brazil.

2- PhD, Assistant Professor, Department of Dental Materials and Operative Dentistry, University of Oeste Santa Catarina, Joaçaba, SC, Brazil.

3- MSc, PhD student, Department of Dental Materials, School of Dentistry, University of São Paulo, São Paulo, SP, Brazil.

4- PhD, Associate Professor, Department of Dental Materials, School of Dentistry, University of São Paulo, São Paulo, SP, Brazil.

5- PhD, Associate Professor, Department of Operative Dentistry, School of Dentistry, University of São Paulo, São Paulo, SP, Brazil.

Corresponding address: Dr. Alessandro Dourado Loguercio - Departamento de Materiais Dentários e Dentística - Faculdade de Odontologia - UNOESC - R. Getúlio Vargas, 2125 - 89600-000 - Joaçaba, SC, Brazil - Phone/ Fax: +55-49-3551-2004 - e-mail:aloguercio@hotmail.com

Received: December 19, 2006 - Accepted: August 21, 2007

\begin{abstract}
$T_{\mathrm{h}}$

he aim of this study was to evaluate the early and 12-month bond strength of two adhesive systems (Single Bond-SB and One Step-OS) applied to demineralized dentin (WH) and demineralized/NaOCl-treated dentin (H). Twenty flat dentin surfaces were exposed, etched, rinsed and slightly dried. For the $\mathrm{H}$ groups, a solution of $10 \% \mathrm{NaOCl}$ was applied for $60 \mathrm{~s}$, rinsed (15 s) and slightly dried. The adhesives were applied according to the manufacturer's instructions and composite resin crowns were incrementally constructed. After $24 \mathrm{~h}$ (water- $37^{\circ} \mathrm{C}$ ), the specimens was sectioned in order to obtain resin-dentin sticks $(0.8$ $\left.\mathrm{mm}^{2}\right)$. The specimens were tested in microtensile $(0.5 \mathrm{~mm} / \mathrm{min})$ immediately (IM) or after 12 months of water storage (12M). The data (MPa) were subjected to ANOVA and Tukey's test $(\alpha=0.05)$. Only the main factors adhesive and time were significant ( $\mathrm{p}=0.004$ and $\mathrm{p}=0.003$, respectively). SB (42.3 \pm 9.1 ) showed higher bond strengths than OS (33.6 \pm 11.6$)$. The mean bond strength for IM-group (42.5 \pm 8.7$)$ was statistically superior to $12 \mathrm{M}(33.3 \pm 11.8)$. The use of $10 \% \mathrm{NaOCl}$, after acid etching, did not improve the immediate and the long-term resin-dentin bond strength.
\end{abstract}

Uniterms: Dentin-bonding agents; Dentin; Tensile strength.

\section{INTRODUCTION}

The retention and sealing provided by current adhesive systems rely on hybrid layer formation. However, there are still difficulties concerning the monomer infiltration within the collagen network. When demineralized dentin is air-dried, collagen fibrils are brought closer together, resulting in the collapse of the organic matrix that reduces the permeability of the demineralized zone ${ }^{12}$. This has been shown to cause marked reduction of the bond strengths to dentin ${ }^{21}$. Excess of water, on the other hand, causes the dilution of resin monomers and phase separation of the hydrophobic and hydrophilic moieties which ultimately compromises resin infiltration ${ }^{25}$ and avoids an adequate polymerization of resin monomers ${ }^{14}$.

The above mentioned issues highlight that the maintenance of demineralized collagen network, exposed by acid etching is critical. In addition, the total depth of dentin demineralization is not fully infiltrated by monomers which leaves an exposed collagen network, close to the unaffected dentin, susceptible to hydrolytic degradation over time ${ }^{2,21}$. Based on that, the use of sodium hypochlorite
( $\mathrm{NaOCl})$, as a nonspecific proteolytic agent, could be useful because it eliminates the collagen network exposed by acid etching ${ }^{6}$ reducing the technique sensitivity related to wet bonding ${ }^{20}$.

When deproteinization is performed, reports on early bond strength are controversial ${ }^{6,23}$. However, there is no report about the longevity of such adhesive interface after water storage. When adhesives are applied to dentin in a conventional manner, significant decreases in the resindentin bond strengths and higher nanoleakage occur after prolonged water storage (6 to 36 months) ${ }^{2,7,24}$. Essentially two main components of the hybrid layer are susceptible to degradation over time: the organic constituent, represented by the naked collagen fibrils, not encapsulated by resin monomers, or the polymer formed among the collagen fibrils, after light activation ${ }^{21}$. If the collagen fibrils are more prone to degradation, as suggested by some authors ${ }^{7,8}$, it is likely that the bonding interfaces formed after deproteinization with sodium hypochlorite are more resistant to water storage than those bonds produced conventionally.

A recent benefit of $\mathrm{NaOCl}$ treatment of demineralized dentin was reported by Pioch, et al. ${ }^{18}$ and Chersoni, et al. ${ }^{3}$. 
Pioch, et al. ${ }^{18}$ showed that the application of sodium hypochlorite for $60 \mathrm{~s}$, reduced silver penetration in the porosities located close to unaltered mineralized dentin and within the superficial collagen-rich fibrous network. Chersoni, et al. ${ }^{3}$ showed that the dentin pre-treatment reduces the water movement through hybrid layer reducing the long-term degradation of resin bonds.

Hence, the purpose of this in vitro study was to evaluate the early and 12-month microtensile bond strength of twostep etch-\&-rinse adhesive systems applied to etched or etched and deproteinized dentin. The hypothesis to be tested is that the bond strength of adhesive systems applied to etched and deproteinized dentin is not affected by 12 months of water storage.

\section{MATERIALAND METHODS}

Two different solvent-based, etch-\&-rinse adhesive systems were tested: Single Bond (SB - 3M/ESPE, St. Paul, MN, USA), an ethanol/water-based system and One-Step (OS - Bisco, Schaumburg, IL, USA), an acetone-based system. Their composition, application mode and batch number are displayed in Table 1.

Twenty extracted, caries-free human third molars were used. The teeth were collected after granting the patient's informed consent under a protocol approved by the University of São Paulo Institutional Review Board. The teeth were disinfected in $0.5 \%$ chloramine, stored in distilled water and used within six months after extraction. The teeth were allocated in four experimental groups of five teeth for each tested condition.

A flat dentin surface was exposed after wet grinding the occlusal enamel on 180-grit SiC paper. The enamel-free, exposed dentin surfaces were further polished on wet 600grit silicon-carbide paper for $60 \mathrm{~s}$ to create a standardized smear layer.

The adhesive systems were applied according to the manufacturers' instructions in half of the sample (Table 1). The other half was acid etched with $37 \%$ phosphoric acid, rinsed and then conditioned with $10 \%$ sodium hypochlorite solution for $60 \mathrm{~s}$ (Table 1). The dentin surfaces were washed thoroughly (15 s) and air-dried. Then, they were rewetted using a micropipette (Pipetman, Gilson, NY, USA). An amount of 3.5 and $1.5 \mathrm{~mL}$ of water was used for OS and SB, respectively, before the application of adhesive systems. ${ }^{21}$

The adhesives were light activated for $10 \mathrm{~s}$ using a VIP light unit (Bisco, Schaumburg, IL, USA) with a light intensity of $600 \mathrm{~mW} / \mathrm{cm}^{2}$. The time elapsed between rewetting and adhesive application was the time required to open the bottles, pour the adhesive on the microbrush and take it to the tooth surface. Resin composite build-ups (Z-250; 3M/ ESPE, St. Paul, MN, USA) were constructed on the bonded surfaces in 1-mm increments that were individually light activated for $30 \mathrm{~s}$ using the same light unit and light intensity. All bonding procedures were carried out by a single operator at a room temperature of $24^{\circ} \mathrm{C}$ and $75 \%$ relative humidity.

After storage of the bonded teeth in distilled water at $37^{\circ} \mathrm{C}$ for $24 \mathrm{~h}$, they were longitudinally sectioned in both " $\mathrm{x}$ " and " $y$ " directions across the bonded interface with a diamond saw in a Labcut 1010 machine (Extec Corp., Enfield, CT, USA) to obtain sticks with a cross-sectional area of approximately $0.8 \mathrm{~mm}^{2}$.

The number of premature debonded sticks (D) per tooth during specimen preparation was recorded. Specimens originated from the areas immediately above the pulp chamber had their remaining dentin thickness (RDT) measured with a digital caliper and recorded to verify the dentin depth (Absolute Digimatic, Mitutoyo, Tokyo, Japan). The cross-sectional area of each stick was measured with a digital caliper to the nearest $0.01 \mathrm{~mm}$ and recorded for posterior calculation of the bond strength.

The bonded sticks originated from the same teeth were randomly divided and assigned to be tested immediately (IM) or after 12 months of distilled water storage (12 M) containing $0.4 \%$ sodium azide ${ }^{2}$ at $37^{\circ} \mathrm{C}$. The storage solution

TABLE 1- Materials, manufacturers and corresponding batch numbers

\begin{tabular}{|c|c|c|c|}
\hline dhesive systems & Composition & Application mode & Batch numbe \\
\hline $\begin{array}{l}\text { Single Bond } \\
\text { (3M ESPE) }\end{array}$ & $\begin{array}{l}\text { 1. Scotchbond - } 37 \% \text { phosphoric acid } \\
\text { 2. Adhesive - Bis-GMA, HEMA, } \\
\text { dimethacrylates, polyalquenoic acid } \\
\text { copolymer, initiators, water and ethanol }\end{array}$ & $\begin{array}{l}\text { Without NaOCl treatment: } \\
\text { a, b, c, e1, f, g, h } \\
\text { With NaOCl treatment: } \\
\text { a, b, c, d, b, c, e1, f, g, h }\end{array}$ & $\mathrm{OEH}$ \\
\hline $\begin{array}{l}\text { One Step } \\
\text { (Bisco) }\end{array}$ & $\begin{array}{l}\text { 1. Uni-Etch }-32 \% \text { phosphoric acid } \\
\text { 2. Adhesive - Bis-GMA, BPDM, HEMA, } \\
\text { initiator and acetone }\end{array}$ & $\begin{array}{l}\text { Without } \mathrm{NaOCl} \text { treatment: } \\
\mathrm{a}, \mathrm{b}, \mathrm{c}, \mathrm{e} 2, \mathrm{f}, \mathrm{g}, \mathrm{h} \\
\text { With NaOCl treatment: } \\
\mathrm{a}, \mathrm{b}, \mathrm{c}, \mathrm{d}, \mathrm{b}, \mathrm{c}, \mathrm{e} 2, \mathrm{f}, \mathrm{g}, \mathrm{h}\end{array}$ & 01007932 \\
\hline
\end{tabular}

$\mathbf{a}$ - acid-etch (15s); $\mathbf{b}$ - rinse (15s); c - air-dry (30s); d - application of 10\% sodium hypochlorite for 60 s; e1 - dentin rewetted with $1.5 \mathrm{ml}$ of water; $\mathbf{e} 2-$ dentin rewetted with $3.5 \mathrm{ml}$ of water; $\mathbf{f}$ - two coats of adhesive systems, brushed for $10 \mathrm{~s}$ each; $\mathbf{g}-$ airdry for $10 \mathrm{~s}$ at $20 \mathrm{~cm}$; $\mathbf{h}$ - light-cure $\left(10 \mathrm{~s}-600 \mathrm{~mW} / \mathrm{cm}^{2}\right)$ 
was not changed because it maximizes degradation. The $\mathrm{pH}$ was monitored monthly.

At each storage time period, individual bonded sticks were attached to a microtensile testing with cyanoacrylate resin (Zapit, Dental Ventures of North America, Corona, CA, USA) and subjected to a tensile force in a universal testing machine (EMIC, São José dos Pinhais, PR, Brazil) at a crosshead speed of $0.5 \mathrm{~mm} / \mathrm{min}$.

The failure modes were evaluated at 400X (HMV-2, Shimadzu, Tokio, Japan) and classified as cohesive (failure exclusive within dentin or resin composite, C), adhesive (failure at resin/dentin interface - A), or adhesive/mixed (failure at resin/dentin interface that included cohesive failure of the neighboring substrates, $\mathrm{A} / \mathrm{M}$ ).

The average bond strength of each group was calculated and expressed as an index that assumes the relative contribution of the different failure modes to the overall performance of that specific group ${ }^{21}$.

A three-way repeated measures ANOVA (material vs. surface treatment vs. time) and Tukey's multiple-comparison test were used to analyze the data at $\alpha=0.05$. The statistical model took into consideration the multiple specimens obtained from the same tooth.

\section{RESULTS}

Table 2 shows the averages for all experimental groups. Three-way ANOVA did not detect any statistically significant effects for the triple and double interactions. The use of sodium hypochlorite has not improved the mean bond strength for both adhesives, as this factor was not significant $(\mathrm{p}>0.05)$.

A significant effect was detected for the factors adhesive system and time on the bond strength to dentin ( $p=0.004$ and $\mathrm{p}=0.003$, respectively). Table 3 shows the averages for each adhesive system and each period of time. Lower bond strengths were detected for OS $(\mathrm{p}<0.05)$. Regarding the longterm bond strengths, Table 3 shows a significant drop on bond strengths after a period of 12 months for both systems $(\mathrm{p}<0.05)$.

\section{DISCUSSION}

While the acid etching alone removes hydroxyapatite and exposes the hydrate intertubular collagen network, the posterior deproteinization of this demineralized dentin layer, removes the collagen and exposes several lateral secondary tubules that was not observed on etched dentin surfaces ${ }^{9}$. Thus, dentin turns into a porous structure with multiple irregularities, rich in hydroxyapatite crystals and higher wettability similar to etched ename ${ }^{26}$. The results of this study demonstrated that both substrates can lead to similar bond strengths, as these values were unaffected by the surface treatment after acid etching.

The literature on this matter is rather controversial. The findings of this study are in accordance with the outcomes from other authors, reporting unaltered bond strengths to dentin when $10 \%$ sodium hypochlorite was used ${ }^{6,10,20}$, even when employing different solvent-based adhesive systems. Others researchers reported that bond strengths to dentin is reduced ${ }^{15,28}$, regardless of the adhesive system employed. However, other groups found that the treatment of demineralized dentin with $\mathrm{NaOCl}$ is dependent on the adhesive system employed ${ }^{4,19}$. These inconsistencies in the literature avoid the widespread use of this technique, as its performance is erratic.

Yamauti, et al. ${ }^{29}$ and Yoshida, et al..$^{30}$ have demonstrated a deterioration on the resin-dentin bond strengths when a total-etch adhesive was stored in $10 \% \mathrm{NaOCl}$ for 1 to 5 hours. According to the authors, this bond deterioration was likely due to the deproteinization effect of $\mathrm{NaOCl}$ on the collagen-rich layer, not encapsulated by resin, beyond the hybrid layer.

Based on that, these naked collagen fibrils started being blamed for the reported degradation of resin-dentin bonds $s^{7,8}$

TABLE 3- Bond strength means (MPa) and standard deviation for each adhesive system and testing period*

\begin{tabular}{|c|c|}
\hline \multicolumn{2}{|c|}{ Adhesive Systems } \\
\hline SB & os \\
\hline $42.3 \pm 9.14 a$ & $33.6 \pm 11.6 b$ \\
\hline \multicolumn{2}{|c|}{ Testing period } \\
\hline Immediate & 12 months \\
\hline $42.5 \pm 8.7 c$ & $33.3 \pm 11.7 c$ \\
\hline
\end{tabular}

TABLE 2- Bond strength means (MPa) and standard deviation for adhesive systems applied conventionally or after deproteinization

\begin{tabular}{lcccc}
$\begin{array}{l}\text { Sodium Hypochlorite } \\
\text { Adhesive/ Time }\end{array}$ & IM & Without & & With \\
\hline SB & $47.7 \pm 7.2$ & $\mathbf{1 2 M}$ & IM & $\mathbf{1 2 M}$ \\
OS & $36.5 \pm 9.2$ & $39.4 \pm 14.1$ & $41.0 \pm 4.9$ & $36.0 \pm 8.5$ \\
& & $29.4 \pm 6.9$ & $45.9 \pm 6.8$ & $23.5 \pm 9.0$ \\
\hline
\end{tabular}


and recently Pashley, et al. ${ }^{13}$ showed that collagen degradation occurred over time, via host-derived matrix metalloproteinases (MMPs) that are released slowly over time, even in absence of bacteria.

In fact, this can explain the bond strength degradation that occurred to the conventionally bonded groups, but cannot explain the degradation of $\mathrm{NaOCl}$-treated groups after 12 months of water storage. A significant resin-dentin bond strength reduction occurred with $\mathrm{NaOCl}$, as also demonstrated in a previous study ${ }^{17}$. Although we have not conducted SEM and TEM studies, it can be postulated, from literature findings, that the $\mathrm{NaOCl}$-treated surfaces seem to be free of loose collagen fibrils ${ }^{10,16}$. The absence of naked collagen fibrils suggests that the polymer formed by light curing of adhesives could be degraded over the testing period. Hydrophilic resins, such as those present in the current adhesives, are highly prone to absorb water ${ }^{1}$. Since all adhesives used in the present study contain significant amounts of hydrophilic monomers, water sorption over time can also be regarded as a contributor to the observed reduction in bond strengths. In addition, failure in removing all residual water entrapped in the deepest regions of demineralized and demineralized and deproteineized dentin induces the formation of poorly polymerized polymer chains $^{14}$, that would be weaker and less stable over time than those formed in water-free regions.

The use of $\mathrm{NaOCl}$ represents an extra step among several crucial others on dentin bonding and one may not assure a superior performance when the dentin deproteinization is performed after acid etching ${ }^{5,22,27}$. For instance, Ferrari, et al. ${ }^{5}$ conducted an in vivo/in vitro study, and evaluated the efficacy of $\mathrm{NaOCl}$ application on microleakage, both in occlusal and cervical margins of the restorations, after a clinical service of 60-90 days. The authors observed a better marginal sealing in cavities not treated with $\mathrm{NaOCl}$. Additionally, the presence of reactive residual free-radicals as a result of the oxidizing action of $\mathrm{NaOCl}$, may compete with the propagation vinyl free-radicals generated during light-activation of the adhesive, resulting in premature chain termination and incomplete polymerization ${ }^{11}$. Therefore, the use of this technique should be avoided in a clinical basis, as there is little evidence of its effectiveness.

\section{CONCLUSIONS}

The use of $10 \% \mathrm{NaOCl}$ for 1 min after dentin demineralization did not improved the bond strength to dentin either immediately or after a 1-year period.

\section{ACKNOWLEDGEMENTS}

This study was partially supported by CAPES and CNPq Grants (551049/2002-2; 350085/2003-0; 302552/2003-0 and 474225-2003-8).

The authors of this study are very grateful for the help provided by Dr. Jack Lemmons from the University of
Alabama, Mr. Preston Beck and Ms. Ruth Aponte and Camilo Machado from the Ohio Sate of University.

\section{REFERENCES}

1- Burrow MF, Inokoshi S, Tagami J. Water sorption of several bonding resins. Am J Dent. 1999;12:295-8.

2- Burrow MF, Satoh M, Tagami J. Dentin bond durability after three years using a dentin bonding agent with and without priming. Dent Mater. 1996;12:302-7.

3- Chersoni S, Suppa P, Breschi L, Ferrari M, Tay FR, Pashley DH, et al. Water movement in the hybrid layer after different dentin treatments. Dent Mater. 2004;20:796-803.

4- De Castro AK, Hara AT, Pimenta LA. Influence of collagen removal on shear bond strength of one-bottle adhesive systems in dentin. J Adhes Dent. 2000;2:271-7.

5- Ferrari M, Mason PN, Vichi A, Davidson CL. Role of hybridization on marginal leakage and bond strength. Am J Dent. 2000;13:329-36.

6- Gwinnett AJ. Altered tissue contribution to interfacial bond strength with acid conditioned dentin. Am J Dent. 1994;7:243-6.

7- Hashimoto M, Ohno H, Kaga M, Endo K, Sano H, Ogushi H. In vivo degradation of resin-dentin bonds in humans over 1 to 3 years. J Dent Res. 2000;79:1385-91.

8- Hashimoto M, Tay FR, Ohno H, Sano H, Kaga M, Yiu C, et al. SEM and TEM analysis of water degradation of human dentinal collagen. J Biomed Mater Res B Appl Biomater. 2003;66:287-98.

9- Inai N, Kanemura N, Tagami J, Watanabe LG, Marshall SJ, Marshall GW. Adhesion between collagen depleted dentin and dentin adhesives. Am J Dent. 1998;11:123-7.

10- Kanca J, Sandrik J. Bonding to dentin. Clues to the mechanism of adhesion. Am J Dent. 1998;11:154-9.

11- Lai SCN, Mak YF, Cheung GSP, Osorio R, Toledano M, Carvalho $\mathrm{RM}$, et al. Reversal of compromised bonding to oxidized etched dentin. J Dent Res. 2001;80:1919-24.

12- Pashley DH, Agee KA, Nakajima M, Tay FR, Tay FR, Carvalho $\mathrm{RM}$, et al. Solvent-induced dimensional changes in EDTAdemineralized dentin matrix. J Biomed Mater Res. 2001;56:273-81.

13- Pashley DH, Tay FR, Yiu C, Hashimoto M, Breschi L, Carvalho $\mathrm{RM}$, et al. Collagen degradation by host-derived enzymes during aging. J Dent Res. 2004;83:216-21.

14- Paul SJ, Leach M, Rueggeberg FA, Pashley DH. Effect of water content on the physical properties of model dentine primer and bonding resins. J Dent. 1999;27:209-14.

15- Perdigão J, Lopes M, Geraldeli S, Lopes GC, Garcia-Godoy F. Effect of a sodium hypochlorite gel on dentin bonding. Dent Mater. 2000;16:311-23.

16- Perdigão J, Thompson JY, Toledano M, Osorio R. An ultramorphological characterization of collagen-depleted etched dentin. Am J Dent. 1999;12:250-5.

17- Pimenta LA, Amaral CM, Bedran de Castro AK, Ritter AV. Stability of dentin bond strengths using different bonding techniques after 12 months: total-etch, deproteinization and self-etching. Oper Dent. 2004;29:592-8. 
18- Pioch T, Kobaslija S, Huseinbegovic A, Müller K, Dörfer CE. The effect of $\mathrm{NaOCl}$ treatment on nanoleakage formation. J Biomed Mater Res. 2001;56:578-83.

19- Prati C, Chersoni S, Pashley DH. Effect of removal of surface collagen fibrils on resin - dentin bonding. Dent Mater. 1999;15:32331.

20- Reis A, Bozzo A, Bocangel JS, Kraul A, Matson E. Influence of collagen on the tensile bond srength to wet and dry dentin. Rev Pósgrad USP. 2000;7:133-9.

21- Reis A, Loguercio AD, Carvalho RM, Grande RH. Durability of resin dentin interfaces: effects of surface moisture and adhesive solvent component. Dent Mater. 2004;20:669-76.

22- Saboia VP, Pimenta LA, Ambrosano GM. Effect of collagen removal on microleakage of resin composite restorations. Oper Dent. 2002;27:38-43

23- Saboia VP, Rodrigues AL, Pimenta LA. Effect of collagen removal on shear bond strength of two single-bottle adhesive systems. Oper Dent. 2000;25:395-400.

24- Sano H. Microtensile testing, nanoleakage, and biodegradation of resin-dentin bonds. J Dent Res. 2006;85:11-4

25- Tay FR, Gwinnett JA, Wei SH. Micromorphological spectrum of acid-conditioned dentin following the application of a water-based adhesive. Dent Mater. 1998;14:329-38.

26- Toledano M, Osorio R, Perdigão J, Osorio E. Effect of acid etching and collagen removal on dentin wettability and roughness. J Biomed Mater Res. 1999;47:198-203.

27- Torres CRG, de Araujo MA, Torres AC. Effects of dentin collagen removal on microleakage of bonded restorations. J Adhes Dent. 2004;6:33-42.

28- Uceda-Gómez N, Reis A, Carrilho MRO, Loguercio AD, Rodrigues Filho LE. Effect of sodium hypochlorite on the bond strength of an adhesive system to superficial and deep dentin. J Appl Oral Sci. 2003;11:223-8.

29- Yamauti M, Hashimoto M, Sano H, Ohno H, Carvalho RM, Kaga $\mathrm{M}$, et al. Degradation or resin-dentin bonds using $\mathrm{NaOCl}$ storage. Dent Mater. 2003;19:399-405.

30- Yoshida E, Hashimoto M, Hori M, Kaga M, Sano H, Oguchi H. Deproteinizing effects on resin-tooth bond structures. J Biomed Mater Res B Appl Biomater. 2004;68:29-35. 